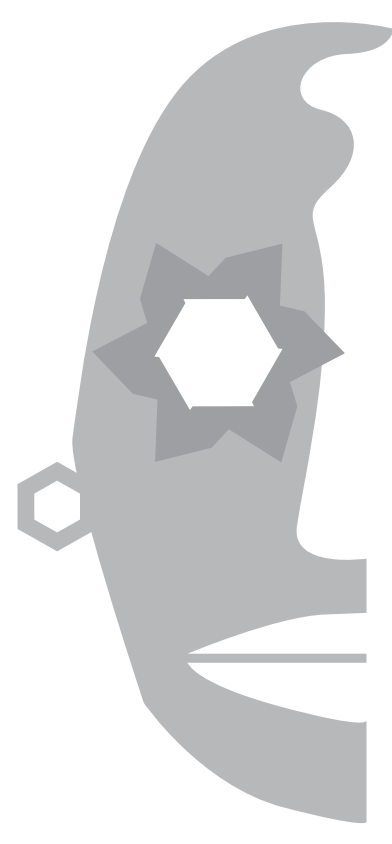

Ana Lorena Carrillo Padilla Universidad Autónoma de Puebla

\title{
Historia y persona. Diarios y cartas del conflicto armado en Centroamérica
}

\section{Resumen}

En el presente artículo se hace referencia a formas y modalidades de escritura autobiográfica: dos "diarios" y un epistolario, producidos todos en el contexto de las guerras centroamericanas de los años ochenta del siglo pasado. Las comillas señalan la ambigüedad genérica de los dos textos que se presentan como diarios. El propósito es mostrar ejemplos de configuración de esta escritura en escenarios distintos, pero marcados todos por la violencia de aquella circunstancia histórica.

Palabras clave: guerra; correspondencia; conflicto; testimonio; Centroamérica.

\section{Abstract}

This article refers to methods and styles of autobiographical writing: two "diaries" and a collection of letters written in the context of the Central American wars during the 1980s. The quotation marks are used here to indicate the generic ambiguity of the two texts represented as diaries. Our objective is to illustrate how these writings have been constructed in different scenarios, all marked by the violence of those historical circumstances.

Keywords: war; correspondence; conflict; testimony; Central America. 


\section{Diario de Ignacio. Escritura intervenida}

Ignacio Bizarro Ujpán, autor del primero de los diarios que se revisan, es un campesino indígena t'zutujil del departamento de Sololá, en la zona del lago de Atitlán, Guatemala; el nombre es el pseudónimo de quien es más conocido en la literatura testimonial como "el otro de Rigoberta", según el título del artículo de Marc Zimmerman (2002), referido a este texto y al mucho más conocido testimonio de Rigoberta Menchú. De hecho, el nombre real es desconocido. Solicitado, traducido y editado por el antropólogo James D. Sexton, la serie de cuatro volúmenes que conforman la totalidad del "Diario" fue publicada en inglés en distintos años y, hasta la fecha, no existe versión en español. En el presente articulo, solamente comentaremos el tercero de los volúmenes: Ignacio: The Dairy of a Maya Indian of Guatemala (1992), por ser este el que abarca los años de 1983 a 1987, los más álgidos del conflicto armado en Guatemala. ${ }^{1}$

Para empezar, la convención de que el diario es una variante de las escrituras del yo tiene, en este caso, un primer quiebre con el hecho de que el autor, a quien debe remitirse la voz en primera persona, se presenta a través de un pseudónimo. Este desplazamiento, que se puede entender por el contexto social, político y de producción de la obra, afecta, como las otras condiciones que se exponen a continuación, las características del texto, acentuando sus rasgos ambivalentes entre géneros autobiográficos y académicos. En primer lugar, las escasas explicaciones sobre el proceso de edición y traducción al inglés llevan al lector a suponer como posible que el diario original se haya escrito en español y no en t'zutujil, que es la legua materna del autor. Que no exista una versión publicada en ninguno de estos idiomas habla del interés estrictamente académico extranjero para el que fue solicitado y publicado, lo que señala determinados destinatarios, funciones y fines. Segundo, el carácter de la intervención realizada por el antropólogo que, como se dijo antes, no es explicada a profundidad, puede establecerse a partir de las secciones de las que es autor explícito: Agradecimientos, Introducción, Epílogo, Apéndice, Notas, Glosario y Referencias; todo un dispositivo paratextual que enmarca y controla al texto. Con estos parámetros básicos el lector accede, tanto a una subjetividad individual que llega al público con las notables intervenciones anotadas, como a una narración de la violencia que fue cercando el medio rural guatemalteco y la vida diaria de sus habitantes durante los años del conflicto armado. A continuación, una de las entradas da cuenta de esta situación:

1 Los otros tres volúmenes son: Son of Tecun Uman: a Maya Indian Tells His Life Story (1981), que abarca de 1941 a 1977; Campesino: the Diary of a Guatemalan Indian (1985), que cubre de 1977 a 1983 y Joseño: Another Mayan Voice Speakes from Guatemala (2001), que abarca de 1987 a 1998. 
Mi amigo Francisco no quiere colaborar como Comisionado Militar Secreto. 19 Febrero 1984.

[...] mi amigo Francisco medijo que lo había llamado el Comisionado Militar para incluirlo como colaborador de una investigación secreta de diferentes organizaciones para ver si la gente dice cosas malas del ejército o contra el gobierno militar. Ese amigo medijo que tuviera más cuidado en las reuniones de la cooperativa porque es seguro que en San José hay tres hombres colaborando como agentes secretos. Francisco me dijo que él no quería porque tiene miedo [...] (Ujpán y Sexton, 1992, p. 71) (énfasis mío)².

Una subjetividad acotada y con escaso margen para la intimidad emerge, sin embargo, por entre la información a través de la evidente modalidad "oral" de la escritura. El sujeto de la enunciación es, o pretende ser, observador “objetivo" más que protagonista de los hechos narrados, utilizando para ello varias estrategias, entre ellas la de privilegiar el discurso descriptivo y no aludir, sino muy escuetamente, a sus sentimientos:

\section{Tragedia en Viernes Santo. 20 Abril 1984.}

Para mí fue día de descanso. No trabajé en Viernes Santo, sólo estuvimos recordando la muerte de Nuestro Señor Jesucristo. Mucha gente estuvo haciendo alfombras de aserrín y flores en las calles para recibir la procesión de Jesús crucificado. También nosotros queríamos recibir la procesión. Entonces Ignacito fue al campo a buscar flores para hacer una pequeña decoración en la calle, pero por mala suerte Ignacito cayó de un árbol y quebró su pie, además se golpeó su cabeza. El sangró mucho (Ujpán y Sexton, 1992, p. 83)³.

Pueden observarse otras marcas de intervención discursiva en las secciones de preguntas y respuestas que figuran al inicio o en medio de muchas entradas del diario -en cursiva para distinguirlas del discurso de Bizarro-, estableciéndose así la extraña (para el género del diario íntimo, pero no para el del diario de campo o de investigación) intromisión de un discurso ajeno (el del editor/traductor). Se trata de otro sujeto, con voz propia, cuya función aparente es propiciar o asumir la aclaración o la ampliación de la información. De este modo, el texto incorpora

2 Traducción mía aquí y en las otras citas de este texto. “(...) my friend Francisco told me that he was called by the military comissioner to be included as a collaborator of a secret investigation of different organizations to see whether the people say bad things about the army or against the military government. This friend told me to take more care in the meetings of te coorperative because it's certain that in San José there are three men who are collaborating as secret agents. Francsico told me that he didn't want to do because he was afraid"

3 For me this was a day of rest. I didn't work on Holy Friday; we were just remembering the death of our Lord Jesucristo (sic). A lot of people were making carpets of sand and flowers in the streets to receive the procession of the cucified Jesús. Also, we intended to receive the procession. Then Ignacito went to the field to look for wild flowers to make a little decoration in the street. But for bad luck, Ignacito fell from a tree and broke his foot and, moreover, injured his head. He bled a lot.(...)" 
una suerte de intertextos (tipo entrevista) que rompen el flujo temporal y de la voz propia del diario. El resultado es un texto situado entre el diario íntimo, la entrevista etnográfica (Guber, 2001: 75) 4 y una suerte de diario de campo como lo describe Leo Simmons (Talavesya, 2013: 5) .

El otro punto a destacar es la construcción de una narrativa de aquellos hechos desde un punto de vista ideológico contrario a la guerrilla. Bizarro Ujpán relata en varias de las entradas del diario acciones violentas atribuidas a la guerrilla, término que alterna con el de "terroristas" o "subversivos", los cuales eran usados por el gobierno y el ejército. Por lo demás, no oculta su aversión por aquellos grupos, sus acciones y propuestas, apropiándose del discurso oficial y de su terminología, proceso ocurrido sin duda en la experiencia de tránsito entre su lengua y cultura materna, y la de los ladinos a través del servicio militar y de sus relaciones laborales. Una referencia de contraste posible podría ser el diario de Tomás Choc, campesino indígena k'iché y exdirigente de las Comunidades de Población en Resistencia durante el conflicto armado; es decir, con una perspectiva política opuesta a la de Bizarro Ujpán. Su diario fue hecho público a través de la cinta Distancia, ${ }^{6}$ cuyo guión ficcionaliza la historia del texto y del autor. El filme narra, basándose en algunos hechos reales, la historia de un campesino de edad madura y de sus vicisitudes al acudir al esperado encuentro con su hija, secuestrada años atrás por el ejército, a quien le lleva el diario como prueba de su vínculo emocional y afectivo con ella, a pesar de las circunstancias. En la realidad, Choc perdió a cuatro hijos en el conflicto armado. A diferencia del "diario" de Bizarro Ujpán, el de Choc surge -según el filme- de una voluntad individual y autónoma de comunicación privada. Las breves secuencias de acercamiento a las páginas de la copia dejan ver dibujos que ilustran los relatos del horror vivido por las comunidades durante las incursiones militares. Esos dibujos, cuya función es completar la narración, evocan tanto formas antiguas de escritura como actuales "diarios de campo". El diario de Choc se conoce hoy solamente por medio de esta forma "vicaria" e intervenida que es mostrada en la cinta: una copia realizada

4 "La entrevista es una estrategia para hacer que la gente hable sobre lo que sabe, piensa y cree (Spradley, 1979: 9), una situación en la cual (el investigador-entrevistador) obtiene información sobre algo interrogando a otra persona (entrevistado, respondente, informante). Esta información suele referirse a la biografía, al sentido de los hechos, a sentimientos, opiniones y emociones, a las normas o estándares de acción, y a los valores o conductas ideales".

5 No ha sido posible encontrar una definición del tipo de diario por encargo como el de Ignacio; sin embargo, consultando la técnica utilizada por Leo W. Simmons en Sun Chief, el diario del informante o (como actualmente se prefiere) el interlocutor, realizado a pedido del etnólogo sería como una continuación del diario de campo realizado por este. Es así como Simmons lo explica en la Introducción al indicar que su informante, Don C. Talayesva, estaba advertido de que debía escribir su propio diario al momento en que Simmons dejara la localidad (Oraibi) y que recibiría un pago de siete centavos (de dólar) por página escrita. El trabajo de campo de Simmons tuvo lugar entre 1938 y 1941.

6 Ficha técnica. Título: Distancia, Director: Sergio Ramírez, Productor: Joaquín Ruano, Año producción: 2011 Formato: DVD Duración: largometraje -70 min., País de producción Guatemala Subtitulado Inglés. 
por una artista plástica de la Ciudad de Guatemala, quien se basó para hacerla en imágenes de video: una imagen de una imagen de una imagen del diario original que, así reelaborado en sentido material, se reelabora también en su significado 7 .

Tanto los diarios de Bizarro Ujpan como el de Tomás Choc han pasado, en su trayecto a la vida pública, por intervenciones que provienen de sujetos no pertenecientes al universo cultural, lingüístico ni de clase en el que se produjeron, pero que dejaron marcas sobre los textos mismos o bien sobre el modo en que pueden o deben ser leídos. Imposible dejar de traer a colación sobre este asunto el tema de las luchas históricas por el poder discursivo (Lienhard, 2000; Molloy, 1996), proceso por el cual la ciudad letrada y sus continuadores modernos, intelectuales y académicos, "descubren" o propician discursos de los sectores marginados, poder discursivo que controla la emisión, la difusión y la interpretación de los mensajes públicos (Lienhard, 2000: 790).

La violencia no es sólo la del contexto histórico y tema de estas escrituras; las intervenciones de que han sido objeto los textos y discursos de estos autores y hablantes campesinos indígenas, como una especie de "precio" para ganar el espacio público, muestran también una "violencia" que se ejerce sobre ellos, aun cuando los propios autores lo consientan. No se trata de una violencia que editores o traductores han infligido intencionalmente; nada más lejos de ello puesto que el propósito ha sido, precisamente, dar a conocer las experiencias de los sujetos por considerarlas valiosas. Ambos casos recuerdan, en modo atenuado, la historia de la autobiografía del esclavo Juan Francisco Manzano, tan sugestivamente analizada por Silvia Molloy (1996: 52-77), es decir la historia de la negación de la legibilidad del texto en sus propios términos. En el caso de Ignacio The Diary of a Maya Indian of Guatemala, la mediación (Molloy, 1996: 56), las intervenciones de que es objeto desde su inicio hasta la versión final en inglés, construyen un texto nuevo que, aunque cumple sin duda con los propósitos científicos para los cuales fue concebido, termina por erigirse, en lo que se refiere al sujeto de la enunciación, no en una máscara autobiográfica, ni en la desfiguración señalada por Paul de Man (1991), sino en un eco lejano, perturbadoramente extraño a (o extrañado de) la voz que le da origen.

\section{Elena Paz y Paz: Viñetas del exilio}

Al igual que las anteriores, Ya no tengo palabras (1997) de Elena Paz y Paz de Hurtado (1930-2010), es una historia relativamente oculta, aun considerando que

7 Algunos detalles del proceso de copiado me fueron facilitados en entrevista por la diseñadora Miriam Ugarte, autora de la copia que aparece en la cinta.

8 Utilizo el concepto mediación en el sentido otorgado por Silvia Molloy para explicar el caso de la autobiografía del esclavo Juan Francisco Manzano que recoge, a su vez, el de "testimonios mediatizados", introducido por Elzbieta Sklodowska. 
ha sido ya publicada. Quedó oculta por el escaso tiraje y circulación, así como por el hecho de que las narrativas testimoniales con mayor difusión son casi siempre las de dirigentes o personalidades públicas de alto perfil, y este no es el caso. Finalmente, también por el hecho de que trata el tema del exilio, y el exilio en Centroamérica no ha sido hasta ahora un tema significativo en la agenda pública sobre el conflicto armado. No así el refugio, que es reconocido. Muy lejos del tratamiento que se le ha dado en países como Argentina y Chile, en Centroamérica el exilio no constituye una secuela relevante del conflicto y quienes lo padecieron se han limitado a vivirlo como experiencia privada, despojada de cualquier significación política pública.

A lo sumo, ha sido un tema de limitado interés académico o literario ${ }^{9}$, o se le menciona como incidente dentro de una narrativa testimonial centrada en la militancia y participación en la guerra misma. Así entonces, el texto de Elena Paz y Paz es una excepción. Se trata, como dice su autora, de "una especie de diario", aunque se aproxima a las formas convencionales de la crónica de viajes. Elena Paz y Paz, pedagoga y artista plástica, fue esposa de un conocido médico pediatra guatemalteco, y ambos formaban parte de la clase media acomodada, intelectual y crítica de la Ciudad de Guatemala en el periodo del conflicto. Escritas en español culto, las veintisiete viñetas que componen el texto hacen el recuento de las pequeñas efemérides cotidianas de un exilio de tres años, mientras en el texto se va configurando, además del yo de la voz de la enunciación, un retrato de familia y una narración del tipo del relato de viaje. De hecho, se trata de un sujeto, una vida y una historia en tránsito. Sin las pretensiones ni las posibilidades de una crónica periodística, el texto de Paz y Paz se escribe para ser historia privada y familiar, para ser leída y circular en el entorno íntimo, en cuyo centro se produce ${ }^{10}$, aunque a partir de cierto momento con la intención de ser publicada alguna vez. El título proviene de una de las viñetas, de hecho, la única que tiene una fecha: marzo de 1983. Como se sabe, la ausencia de fechas en un diario contraviene la regla básica del género, por eso el lugar ambiguo que la autora le otorga a su texto: "una especie de diario". Las referencias temporales en el resto del documento están marcadas, en su mayoría, no por fechas, sino por acontecimientos de dos

9 En tiempos recientes, Guadalupe Rodríguez de Ita, Pablo Yankelevich, Nathalie Ludec y Elena Salamanca son algunos - casi todos extranjeros, salvo Salamanca- de quienes se han ocupado del tema del exilio centroamericano desde las ciencias sociales. Marco Antonio Flores y Horacio Castellanos Moya lo trabajaron literariamente.

10 La versión publicada de este texto, que es el que se ha utilizado aquí, se abre con una carta dirigida a la autora por un amigo cercano y su esposa. Esta carta tiene una función precisa en el texto, que es la de servir de aval y justificante de su publicación. Por tratarse de un texto íntimo de carácter autobiográfico, puede pensarse que opera en él el mismo principio que Silvia Molloy advierte en la autobiografía: el de que el autobiógrafo hispanoamericano suele equilibrar cierto sentido de pudor y vanidad sobre la publicación de su vida con una o varias estrategias de justificación. 
órdenes: los del mundo y los de la vida personal cotidiana, más precisamente, de la cotidianidad extraña del exilio.

La significación otorgada a unos y otros establece la relación fundamental entre acontecimiento y persona, no el registro cronológico, que no lo hay. Las pequeñas historias van y vienen en el tiempo, son recuerdos o vivencias presentes y de ese tránsito surgen estados de ánimo de amplio espectro: nostalgia, tristeza, alegría, dolor. En su acepción "clásica", el diario de escritor o intelectual no divaga entre el presente y el pasado, recuerda poco, se ciñe a la disciplina del acontecer del día y es, como lo llama repetidamente Pauls (1996), texto de coyuntura, esclavo del presente. La declaración del diario íntimo sobre su presentismo se ratifica con el ya señalado registro puntual de fechas, días, meses, años y esta es condición sine qua non de la pertenencia de un texto al género (Pauls, 1996: 4). De acuerdo con ello, el texto de Paz y Paz sería "una especie de diario" sólo porque ella misma así lo nombra, en términos estrictos no lo es en absoluto. Pero no se trata aquí de establecer límites y trazar fronteras, sino de situar modalidades discursivas sin objetar su heterogeneidad e hibridismo.

En la "introducción" la autora define, en agosto de 1995, dos años antes de la publicación, esa suerte de "rostro" con que se dota al texto cuando se habla en su nombre por última vez (Molloy, 1996: 11). Ahí reflexiona, en un tiempo posterior a la escritura, sobre la experiencia de la vida y habla una vez más (la última), para decir algo sobre lo que ha escrito antes. Evidentemente, la autora ha hecho una selección para ser publicada o mejor dicho, "salvada". "Salvar algo de lo existente" es el objetivo para la publicación, y aunque dice no tener ningún plan, pocas líneas más adelante señala con claridad la estructura formal que desea: el collage.

No tengo plan definido. He escrito tanto en los últimos años. Páginas de una especie de diario. Poemas surgidos al calor de una emoción o vivencia impactante. Pensamientos sueltos. Todas esas letras se encuentran en cuadernos manuscritos. Quiero salvar algo de lo existente; hacer un collage con pedazos de vidrio, cobre, tejidos varios, hojas y pedruscos del camino (Paz y Paz 1997: 9).

La autora no se esfuerza en buscar justificantes ni coartadas históricas, no publica para que otros aprendan o para dar testimonio, solo quiere "dejar alguna huella" de su paso por este planeta, declaración individualista que hace de estos pequeños relatos de exilio un ejemplar ejercicio de honestidad. No hay aquí esa "coartada" de la que habla Pauls (1996: 5) y que para Molloy (1996: 21) es la justificación de la mezcla de pudor y vanidad que aqueja al autobiógrafo. Las vivencias personales merecen ser "salvadas", por domésticas que sean, y no solo porque a la postre son vivencias colectivas, merecen la salvación porque son huellas de una vida individual. Salvar las pequeñas historias personales de esta guerra para reconstruir el modo en que la vivió la colectividad es, en todo caso, tarea del lector. La nueva casa, el nuevo país, 
las cartas enviadas y recibidas, las versiones falsas pero necesarias de lo que ha ocurrido en el entorno afectivo inmediato constituyen el anecdotario familiar del exilio, y quienes así quieran leerlo verán ahí un fragmento de la historia de la guerra misma.

Se trata de una escritura que, al igual que las otras examinadas, son actos de resistencia y, como tales, afirmativos de la vida. Como el diario del enfermo o del preso, la escritura del exiliado le permite sobrevivir a la violencia del desarraigo. De ahí el inexplicable tono eufórico o esperanzado que todas ellas tienen. Escribir crónicas, diarios o cartas desde la esfera de la intimidad, en medio de una convulsión social y política de la magnitud de los conflictos centroamericanos de la década de los años setenta y ochenta, no parece haber sido una práctica intelectual/intimista del tipo de la escritura de los diarios de intelectuales europeos o norteamericanos analizados por Pauls (1996). Lejos de ello, la "especie de diario" centroamericano, aclimatada a los tiempos y espacios de la región, está en los linderos de la autobiografía, el testimonio, el anecdotario, la crónica, para construir una escritura que, aunque íntima y personal, termina siendo política, familiar y social. Esto es así por el carácter multifuncional de esta escritura que quiere, simultáneamente, relatar hechos, consignarlos a la vez que denunciarlos y contarlos como experiencia del yo y del nosotros.

Retrato de familia a la vez que del yo, Ya no tengo palabras es también la historia de sectores de la clase media radicalizada, colocada en la coyuntura del conflicto entre una lealtad político/familiar con la izquierda revolucionaria y una pertenencia social ajena a los intereses populares. Una clase media que vivió, en efecto, una "impaciencia" puesta a término ideológico por la revolución cubana desde los años sesenta y que, impelida por su fuerza, se puso al frente de la crisis de los años setenta (Torres Rivas, 2009). En realidad, los relatos íntimos de la clase media radical se debaten, como la clase misma, entre discursos de radicalismo político usualmente obvios y otros, menos evidentes, que subyacen a las imágenes y los motivos nostálgicos de lo perdido: familia, casa, bienestar, culturalmente convencionales y hasta conservadores. En Centroamérica, buena parte de los jóvenes combatientes en la guerra se nutrió de esa clase media radical y, sin duda, a ella pertenecieron sus dirigentes. Familias con cierta historia de simpatías democráticas que terminaron arrastradas por el huracán:

Había que continuar la vida de todos los días. Asistir a fiestas, exposiciones, conciertos; aceptar y corresponder invitaciones. No mostrar ninguna anormalidad. No dar el más leve indicio de angustia o preocupación y menos aún, expresar descontento ante la situación imperante. Los hijos veían a sus padres clandestinamente. Un mensajero desconocido hacía los contactos o, a veces, se acudía a llamadas telefónicas imprudentes. Qué ansiedad y angustia ante la noticia del próximo encuentro [...] (Paz y Paz, 1997: 11) 
Hay un tema recurrente en el texto: la dicotomía normal/anormal que alude a la contradicción señalada arriba y al modo en que se vive como experiencia subjetiva. Lo normal es el tiempo sin sobresaltos, tanto el personal y familiar como el social e histórico, es la cotidianidad antes de haber sido rota por la guerra o la que se vive al margen de ella. Lo normal, aunque es también la indiferencia frente a lo que ocurre, se vive como nostalgia de bienestar, orden e integración, deseo: "Todo es normal, menos las noticias aterradoras de la patria. Continúan las masacres, las quemas de las aldeas, el éxodo de sobrevivientes y la creación de aldeas modelo, además de secuestros, desaparecidos, etc.etc. (Paz y Paz, 1997: 21). Lo anormal es todo aquello que se instaura con el quiebre de aquel tiempo. También son anormales las cartas que llegan del frente:

Hay también otras cartas que se tardan por su extraña procedencia. No llegan en sobre con sellos ni son traídas por el correo. Son cartas anormales. A veces papeles terriblemente ajados. Generalmente escritos con letra pequeñísima, quizá para economizar papel. Algunas escritas a máquina con una cinta que permite adivinar los caracteres que casi están en relieve y en algunos casos lo rompen. Muchas de esas cartas anormales han llegado a nuestras manos. Un puñado de piedras preciosas no nos proporcionaría más placer que la vista de estos oscuros papeluchos anormales. (Paz y Paz, 1997,19).

El papel ajado, la letra pequeñísima, la cinta de máquina con que se escriben, todos los pequeños detalles del tiempo anormal adquieren valor de piedras preciosas. El deseo y el rechazo simultáneos de la realidad fracturada por la crisis del tiempo normal/anormal, genera ocasionalmente en el discurso de Paz y Paz construcciones desencajadas. Al material publicado deben sumarse algunas páginas sueltas con el título Vivencias 1982, que son el complemento inédito de las viñetas, compuesto por anotaciones que corresponden al periodo anterior al exilio y más precisamente referidas al episodio que lo motivó. Se trata, nuevamente, de crónicas retrospectivas, más cercanas al recuento cronológico que al diario propiamente dicho. Cubren el periodo entre el 24 de junio y el 29 de julio de 1982 durante la crisis familiar, personal y social creada por el secuestro (detención ilegal) del esposo de Elena Paz y Paz. La recreación del diálogo entre la autora y la esposa del mandatario de entonces, el General Efraín Ríos Montt, es ilustrativa:

Después de unas frases me atreví a pedirle que le pasara a Juan José una carta de mi hijo que reside en los Estados Unidos. En el sobre le escribí: "Amor, todos tus hijos están bien. Besos, Elena" y mi hija escribió "Te amo, Ele". La Sra. Dobló la carta y se la guardó en el bolsillo. -Veremos si permiten que le llegue, dijo. Luego con profunda admiración habló la señora de su esposo, el General y del gobierno de justicia en que estaba empeñado -Dejo a mi esposo en tus manos, le dije. -No, en manos del Señor, replicó María Teresa. Esa fue la despedida. (Paz y Paz, s/f: 2). 
La interacción narrada y la narración misma presuponen, como lo indica Leonidas Morales (2006) para las cartas de petición, un quiebre que suele ser un acontecimiento referencial concreto: un golpe de Estado, la imposición de una dictadura, una guerra interna. El propio emisor es el signo de un orden roto que lo coloca en estado de indefensión. En la interacción narrada y en la narración misma el destinatario de la petición ("que le pasara a Juan José una carta...") es el signo del orden contrario: el poder impuesto por la violencia. Sin más, se trata de la confrontación en la escritura entre la intimidad y el poder.

\section{Cartas desde la clandestinidad: Lil Milagro Ramírez}

El epistolario de Lil Milagro Ramírez (1946-1979) ha sido publicado recientemente en un volumen, compilado y comentado por Miriam Medrano (2013), amiga y compañera de estudios de Lil, en San Salvador. ${ }^{11}$ Compuesta por diversos documentos, fotografías, poemas y cartas escritas entre 1969 y 1973, el propósito de la publicación es de homenaje, como lo señala el título mismo, que resignifica el nombre de pila de la autora de las cartas, separándolo con un signo de puntuación (de Lil Milagro de la Esperanza a Lil: Milagro de la Esperanza). Aunque existe en la publicación también un interés académico y de investigación sobre la memoria histórica en El Salvador, el carácter de la obra es, como reza el poema que abre el volumen, de tributo.

Un hecho que hay que tener en cuenta en la lectura de la mayor parte de estas cartas es que fueron escritas desde la clandestinidad, condición que impone a la escritura huellas distintas a las de la cárcel o el exilio. En la cárcel las normativas institucionales definen lo que puede o no ser escrito y tienen que ver con el binomio autoridad/sometimiento, en tanto en la clandestinidad se trata del de encubrimiento/ descubrimiento. En la clandestinidad la simulación es código de conducta general obligado para todas las partes. La "comedia" de la que hablaba Elena Paz y Paz, a la que estaban forzados ella y su marido es en realidad un extenso tema sociológico y semiótico: el secreto, la simulación y la mentira como conductas asociadas a grupos sociales o políticos, y también como niveles de significación de la realidad. Las identidades superpuestas y la construcción de historias falsas son partes del entramado del secreto, elemento central de la operación clandestina, una metodología que, según dice Fabbri (Estay, 2013), puede conducir al sujeto a transformar los signos haciendo desaparecer su propia sombra, su propio rastro.

Es notable en la mayoría de las cartas de Ramírez la vaguedad o simplificación con que se construye el contexto de emisión del discurso epistolar. Esta parte, generalmente situada en la introducción, suele ocupar en sus cartas unos pocos

11 Es posible encontrar una selección de cuatro cartas en el sitio: http://es.wikipedia.org/wiki/Lil_Milagro_ Ram\%C3\%ADrez . Consultado el 5 de septiembre de 2014. 
renglones que se despachan rápidamente para entrar de lleno en cualquiera de los dos registros señalados antes: o se escribe sobre la situación política, ideas políticas, o afectivamente sobre personas conocidas, hechos familiares, lecturas, recuerdos, etc. La construcción del contexto de emisión -función primordial de las categorías introductoras- se cumple a medias o no se cumple en estas misivas. Así por ejemplo, en la carta a la madre de agosto de 1971 (Medrano, 2013: 61) se pasa directamente de la apertura al cuerpo mismo, sin una introducción que permita al destinatario recrear el contexto de emisión: "Querida queridísima: ¿Has encontrado ya entre mis cosas un libro que tú misma me hiciste, empastado en verde oscuro y que contiene una serie de cartas dirigidas a ti y que comienzan precisamente así: Querida, queridísima?".

El quiebre de la estructura modélica se ajusta, sin embargo, a las necesidades comunicativas del emisor: mantener un vínculo con economía de información. Esa es la razón por la que la contextualización se realiza mucho más adelante y de modo muy general y sin indicaciones concretas de lugar, estado de ánimo o referencia a cartas previas, limitándose a enumerar de modo general algunas actividades: "prepararme", "estudiar", o bien "he escrito algunas cancioncitas" "leo", "También como, duermo, me baño y hago ejercicios (jaja)" (Medrano, 2013: 68). Todo ello, bajo el modelo narrativo de resumen, reduce y acelera no sólo textualmente, sino temporalmente, el relato de una serie de acciones desplegadas a lo largo de un tiempo largo, con evidente intención de no detenerse en ello y restarle importancia.

La estructuración de un diseño epistolar específico a medida de las necesidades del (la) emisor(a) se cumple con creces en varios niveles: construcción del yo, validación de la propia vida, decisiones e ideas, marcos contextuales afectivos claros e insistentes, marcos situacionales de emisión vagos, "presencia" en la ausencia a través de temas familiares, elaboración retórica del lenguaje comunicativo, etc. En todo esto aparecen como trasfondo los temas subjetivos, anímicos de la ansiedad comunicativa, la culpa, el sentido sacrificial cristiano, el dolor de la ausencia, la renuncia y otros marcadores de la subjetividad que permean el discurso testimonial de las guerras centroamericanas, algunos de ellos propiamente femeninos (Carrillo, 2011). La vocación comunicativa de la carta se refuerza, aunque no necesariamente en el plano afectivo, en el caso de los emisores en situación de clandestinidad, al vehicular tanto las tradicionales categorías, contenidos y discursos afectivos familiares de la carta privada común, como otros menos convencionales: los de la polémica, la invectiva, el discurso político o la proclama, que también requieren de comunicabilidad con evidentes pretensiones persuasivas y justificatorias.

Al dolor, miedo y pérdida deben sumarse entonces la ambigüedad y la turbulencia de una comunicación afectiva, fracturada no solo por las circunstancias extratextuales, sino por las meramente textuales y discursivas. La paradoja reside en que 
la introducción de estos géneros repliega y silencia el discurso de la intimidad y los afectos, creando una zona "anormal" de comunicación. Aún más: hay algunos indicios de que aun cuando los temas políticos (con sus respectivos géneros y discursos) sean solicitados por el destinatario, dicha solicitud parece fundada en el apremiante deseo de mantener vivo el hilo comunicativo, aunque sea a costa de un vacío en la comunidad de sentido: “

A ver si de una vez por todas los políticos "de izquierda" que todavía "confían" en la "pureza" de tal proceso electoral se dan cuenta de que tan solo están haciendo el juego al oficialismo, de que por las buenas o las malas, la "vía legal" sólo es legal para los candidatos que al sistema le convienen [...]. (Medrano 2013: 113)

En la correspondencia de Lil Milagro Ramírez no sabemos cómo reaccionan los destinatarios de sus cartas frente a estos segmentos (que muchas veces son de varias páginas), si enmudecen, gritan o responden. Por alusión que hace ella misma a las misivas de las contrapartes, se puede interpretar que sus destinatarios establecen con claridad, aunque no sabemos si explícitamente, modos distintos de recepción de los dos tipos de discursos predominantes en sus cartas, como en la carta dirigida a la madre en agosto de 1971: "Pero no era mi intención meterme con la política". Y más adelante:

[...] yo no quisiera que tú odiaras las causas por las que yo no estoy junto a ti, ¿sería mucho pedirte, madre, que además de comprenderme y perdonarme, quieras saber un poco más de todo lo que me ha conducido a este camino? [...] yo pienso que tú podrías leer algo sobre lo que se ha escrito de esta lucha en toda América y en el mundo, no la admitas si no quieres pero conócela, critícala estúdiala a través de sus documentos y testimonios, estoy segura que esa será la mejor manera de poder entenderme a mí [...]. (Medrano, 2013: 66)

O bien esta otra, también dirigida a la madre en 1972: "Bueno, querida, te dejo por ahora, y te agradezco todo lo que me soportas, y la paciencia que tienes para conmigo". (Medrano, 2013: 131).

¿Qué hay realmente atrás de la sospecha de que los destinatarios no quieren recibir aquellos discursos políticos y de la intención autosaboteada de "no meterse con la política"? Hay, como en el caso de Elena Paz y Paz, una zona de tensión. Escritura y lectura no parecen "co-responder", parecen desfasadas en algún plano comunicativo. Se trata de una tensión que se resuelve en una suerte de silencio, no solamente el impuesto al lector actual por tener a mano únicamente una parte del diálogo, o del que -dentro de la lógica textual- nombra Paz y Paz como incredulidad y estupefacción; son también silencios y enmudecimientos que se instauran ahí donde las palabras y los discursos de la razón, aunque circulen, obstruyen el canal comunicativo de los afectos y, con ello, impiden lo que de cualquier manera sería imposible: ordenar, hacer "normales", restituir la vida íntima ya rota por el conflicto. 


\section{Referencias}

Carrillo Padilla, A.L. (2011). "Reconstrucción del yo desde la Guatemala de postguerra. Textos autobiográficos de militantes". En Ana Lorena Carrillo y Cathereen Coltters Illescas (Ed.), Las Huellas del Yo. Memoria y subjetividad en la escritura de mujeres latinoamericanas, Puebla, Benemérita Universidad Autónoma de Puebla, 259-303

De Man, P. (1991). "La autobiografía como desfiguración". Anthropos: Boletín de información y documentación, (29), 113-118.

Emrett, W. (1964). Fragmentos de un diario en náhuatl. Tlalocan IV, 311-20.

Estay Stange, V. (2013). Entrevista con Paolo Fabbri. Tópicos del seminario, (30), 157-172.

García, C. (2005). Literatura Testimonial Indígena en Guatemala (1987-2001): Victor Montejo Y Humberto Ak'abal. Tesis doctoral. University of Florida. Disponible en VMYH AK'ABAL - 2005 - purl.fcla.edu Consultada junio 2015.

García Calvo, C. (2012). Distancia, un viaje silencioso al corazón de Guatemala, www.latamcinema.com/noticia.php?id=4296 (fecha de consulta en formato $01 / 12 / 2007)$.

Guber, R. (2001). La etnografia: método, campo y reflexividad (Vol. 11). Editorial Norma. Disponible en perio.unlp.edu.ar/.../la_entrevista_etnografica_o_el_arte_de_la_no_direc... Consultado el 9 de julio de 2015

Hierro, M. (1999). La comunicación callada de la literatura: reflexión teórica sobre el diario íntimo. Mediatika: cuadernos de medios de comunicación, (7), 103-127.

Lienhard, M. (2000). "Voces marginadas y poder discursivo en América Latina". Revista iberoamericana, 66(193), 785-798.

Molloy, S. (1996). Acto de presencia: la escritura autobiográfica en Hispanoamérica (Vol. 35). El Colegio de México.

Morales, L. (2006). Cartas de petición: Chile 1973-1989. Editorial Cuarto Propio.

Pauls, A. (1996). Cómo se escribe el diario íntimo: Franz Kafka...[et al.]. El Ateneo.

Ujpán, I. B., \& Sexton, J. D. (1985). Campesino: the diary of a Guatemalan Indian. Univ of Arizona Pr.

. (1990). Son of Tecun Uman: A Maya Indian tells his life story. Waveland PressInc. Segunda edición. 
. (1992). Ignacio: The Diary of a Maya Indian of Guatemala. University of Pennsylvania Press.

. (2001). Joseño: Another Mayan Voice Speaks from Guatemala. UNM Press.

Talayesva, D. C. (2013). Sun chief: The autobiography of a Hopi Indian. Yale University PressTalayesva. Extracto de la Introducción de SImmons es accesible wwww.yalebooks.com, Consultado el 9 de julio 2015.

Torres Rivas, E. (2009). Centroamérica: de la izquierda revolucionaria a la izquierda socialdemócrata, Quorum (22), 41-50. Disponible en http://dspace. uah.es/dspace/handle/10017/11462 Consultado mayo 2015.

Zimmerman, M (2002). "El otro de Rigoberta: Los testimonios de Ignacio Bizarro Ujpán y la resistencia indígena". En John Beverley y Hugo Achúgar (Ed.) La voz del otro. Testimonio, Subalternidad y Verdad narrativa (243256). Guatemala, Universidad Rafael Landívar. 